\title{
Rectal prolapse traumatizes rectal neuromuscular microstructure explaining persistent rectal dysfunction
}

\author{
Matthias Kraemer $^{1}$ (D) Werner Paulus ${ }^{2} \cdot$ David Kara $^{1} \cdot$ Saskia Mankewitz ${ }^{1}$. \\ Stephanie Rozsnoki ${ }^{2}$
}

Accepted: 30 August 2016/Published online: 6 September 2016

(C) The Author(s) 2016. This article is published with open access at Springerlink.com

\begin{abstract}
Purpose Internal rectal prolapse is common and correlates with age. It causes a plug-like physical obstruction and is a major cause of defecation disorder. The progressive distortion of the prolapsing rectum likely causes secondary defects in the rectal wall, which may exacerbate rectal dysfunction. We undertook a prospective observational study to detect and quantify the neurologic and histopathologic changes in the rectal wall.

Methods We examined dorsal and ventral rectal wall specimens from consecutive patients with internal rectal prolapse undergoing stapled transanal rectal resection (STARR). We subjected specimens to histopathologic and neuropathologic assessment, including immunohistochemistry. We also recorded patients' clinical and demographic characteristics and sought correlations between these and the pathologic findings. Results We examined 100 specimens. The severity of rectal prolapse and the extent of descent of the perineum correlated significantly with age. Concomitant hemorrhoidal prolapse was noted in all male patients and in $79 \%$ of female patients. Muscular and neuronal defects were detected in 94 and $90 \%$ of the specimens, respectively. Only four specimens $(4 \%)$ were free of significant structural defects.

Conclusion Rectal prolapse traumatizes the rectum causing neuromuscular defects. The tissue trauma is due to shearing forces and ischemia caused by the intussusception. This initiates a self-
\end{abstract}

Matthias Kraemer

mkraemer@barbaraklinik.de

1 Department of General and Visceral Surgery, Coloproctology, St. Barbara-Klinik, Hamm, Germany

2 Institute of Neuropathology, University-Hospital, Westfälische Wilhelms-Universität, Münster, Germany reinforcing vicious circle of physical and functional obstruction, further impairing rectal evacuation and causing constipation and incontinence. The correlation between extent of prolapse and age suggests that internal rectal prolapse can be considered a degenerative disorder. Neural and motor defects in the wall of the rectum caused by rectal prolapse are likely irreversible.

Keywords Rectal dysfunction $\cdot$ Megarectum $\cdot$ Rectal hyposensitivity $\cdot$ Rectal inertia $\cdot$ Obstructed defecation $\cdot$ Rectal prolapse

\section{Introduction}

The last decade has brought a better understanding of acquired degenerative disorders of the rectum as well as new treatment options. In this context, internal rectal prolapse is recognized as a major cause of defecation disorder. The causal link between internal rectal prolapse and defecation disorder is largely accepted as a pathophysiologic concept known as obstructed defecation syndrome [1-12]. The cause of obstructed defecation is thought to be physical obstruction caused by the plug-like internal prolapse.

Imaging of patients with rectal prolapse - particularly dynamic defecography - often reveals an extremely flaccid and dilated rectum. Resection specimens of prolapsing rectum frequently appear fibrosed and scarred. It would be unlikely that a markedly flaccid, dilated, and intussuscepting rectum still retains the sensorimotor integrity required for evacuation. Conversely, a structurally normal rectum is unlikely to be flaccid enough to undergo intussusception.

The healthy rectum plays central sensory and evacuation roles in defecation. We hypothesized that the mechanics of internal rectal prolapse cause trauma to the rectal wall that in turn leads to sensorimotor impairment of rectal evacuation. 
The confirmation of a causal relationship between prolapse, structural damage, and functional deficit would contribute to our understanding of sensorimotor disturbances of the rectum and might explain why dysfunction may persist despite operative removal of the obstructing prolapse.

The objective of this prospective observational study therefore was to detect and quantify histopathologic changes in rectal wall specimens taken from patients with rectal prolapse undergoing stapled transanal rectal resection (STARR). We sought changes that might indicate coexisting deficits of rectal sensory and motor functions and examined whether there was a correlation between structural changes, patients' demographic characteristics, and clinical findings.

\section{Materials and methods}

We undertook a prospective observational study, recording clinical data from patients with internal rectal prolapse undergoing STARR and subjecting resected specimens to detailed neuropathologic examination. We examined the extent to which defects were found in the mucosa-submucosa, muscularis propria, and connective tissue, as well as the neuronal plexus and cells of Cajal. We also sought correlations between defects, the sex, and age of the patients and clinical findings.

\section{Stapled transanal rectal resection}

In western Europe, STARR has become a standard procedure for the resection of rectocele and to address internal rectal prolapse [1-12]. In carefully selected patients, the procedure is technically straightforward, safe, and generally has good functional outcomes. During surgery, the anterior and posterior rectal segments of the prolapse are usually resected separately and the remaining wound edges are stapled together. Generally, therefore, two separate full thickness specimens of the affected rectal wall are taken.

Although the STARR technique is widely accepted, it is still considered as controversial in some parts. However, possible pros and cons of the STARR procedure are not the issue of our study.

For the purposes of this study, we undertook investigations, made the diagnosis, selected patients for surgery, performed STARR, and managed patients postoperatively according to our current, routine clinical practice.

\section{Histologic and neuropathologic assessments}

Formalin-fixed, paraffin-embedded samples of complete rectal wall were subject to histologic and neuropathologic assessments. All histologic assessment was undertaken at the Institute of Neuropathology of the University Hospital,
Münster, Germany, according to previously published techniques $[13,14]$.

Specimens were stained with hematoxylin and eosin or Elastica van Gieson stains. Immunohistochemical staining was performed for the following antigens: CD117 (Clone cKit, Dako, Glostrup, Denmark, concentration 1:400, boiling pretreatment at $\mathrm{pH}$ 6.1), S100 (Dako, concentration 1:4000, no boiling pretreatment), calretinin (Dako, clone DAK-calret 1, concentration 1:50, boiling pretreatment at $\mathrm{pH} 9.0$ ), and muscle actin (clone HHF35, Dako, concentration 1:400, boiling pretreatment at $\mathrm{pH}$ 6.1). All samples were independently assessed by two raters (WP and SR).

We examined for mucosa prolapse syndrome (manifested by fibromuscular obliteration, crypt atrophy, erosion, and ulceration) and assessed the integrity of the muscularis propria (for layering, atrophy of the circular or longitudinal layer, scarring of the circular or longitudinal layer, or inflammation), connective tissue (quantity and location), the submucosal plexus (for its structure), the myenteric plexus (for quantity of ganglion cells and scarring), the interstitial cells of Cajal (for density), and the general severity of pathology (see also supplemental Fig. 1).

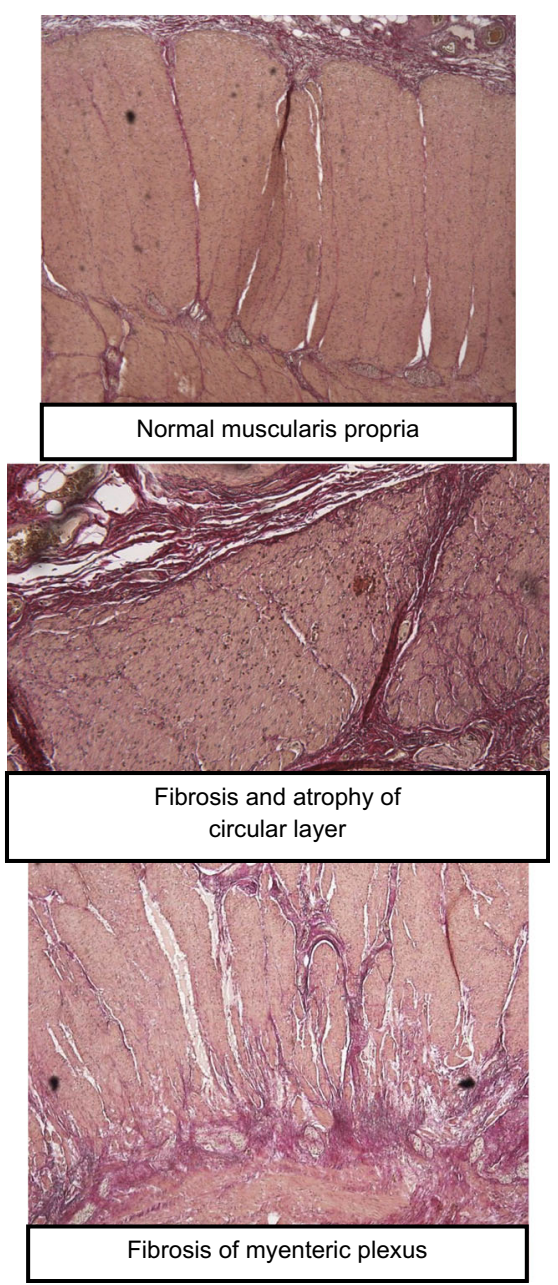

Fig. 1 Examples of some of the histologic findings 
Table 1 Patients' demographic characteristics

\begin{tabular}{lll}
\hline & Number & Age median/average/range (years) \\
\hline Female & 39 & $57 / 58 / 54-80$ \\
Male & 12 & $51 / 52 / / 39-72$ \\
Total & 51 & $54 / 57 / 39-80$ \\
\hline
\end{tabular}

\section{Statistical analysis}

We used the Fisher's exact test, the chi-squared test, and the Kruskal-Wallis test to compare the clinical and histopathologic features of the patients with rectal prolapse (SPSS software, version 20.0; IBM Corporation, Armonk, NY). $P$ values $<0.05$ were considered statistically significant. Statistical support was provided by the Institute of Biostatistics and Clinical Research, Westfälische Wilhelms-Universität, Münster, Germany.

\section{Ethics approval}

Conduct of the study was approved by the local ethics board (2013-629-f-S, Ethikkommission der Ärztekammer Westfalen-Lippe) and registered as a clinical study with our national database (DRKS00005662, Deutsches Register Klinische Studien).

\section{Results}

We collected 100 specimens from 51 consecutive patients diagnosed with obstructed defecation and rectocele/rectal prolapsed, who underwent STARR following our routine preoperative therapeutic and diagnostic protocol (patient demographics; Table 1). Of these, 49 were ventral wall specimens and 51 dorsal wall specimens. Two patients in our cohort only required semicircular STARR, which therefore yielded only one specimen. Four patients who had a previous anorectal operation during the previous 12 months were excluded from the study. Staining was performed on all 100 specimens.

Table 2 Obstetric and gynecologic histories of female patients

\begin{tabular}{lll}
\hline$(n=39)$ & Vaginal delivery & Hysterectomy \\
\hline $16(41 \%)$ & + & - \\
$9(23 \%)$ & + & + \\
$8(21 \%)$ & - & + \\
$6(15 \%)$ & - & - \\
\hline
\end{tabular}

Table 3 Extent of rectal intussusception (RI) versus patient age

\begin{tabular}{lcl}
\hline Rectal intussusception (RI) & Number & $\begin{array}{l}\text { Median/average } \\
\text { age (years) }\end{array}$ \\
\hline RI reaches upper part of anal canal & 6 & $49 / 49$ \\
RI reaches lower part of anal canal & 22 & $54 / 53$ \\
RI reaches external anal ring & 15 & $62 / 62$ \\
RI reaches beyond external anal ring & 6 & $68 / 69$ \\
Not stated & 2 & \\
RI versus age & & $p=0.01$ \\
\hline
\end{tabular}

\section{Clinical characteristics}

The majority of female patients had a history of vaginal delivery $(64 \%)$ and/or hysterectomy (44\%; Table 2$)$. The severity of rectal prolapse and extent of the descending perineum corresponded significantly with age (Tables 3 and 4). Hemorrhoids were present in all male patients and in $74 \%$ of female patients (Table 5). The vast majority of female patients were found to have rectocele (Table 6), again correlating with age.

\section{Histologic changes}

Muscular and neuronal defects were detected in 94 and $90 \%$ of the specimens, respectively (Table 6). Only four specimens from three patients were free of significant histologic or neuropathologic findings (Table 7). Notably, two of these three patients had unremarkable ventral specimens but were nevertheless found to have defects on the opposite side. Only 1 of the 51 patients was found to be free of significant muscular or neuronal defects in both STARR specimens.

\section{Discussion}

Our findings support the hypothesis that internal rectal prolapse formation initiates a vicious circle of progressive structural damage and ensuing loss of function. Internal rectal prolapse is a plug-like intussusception of the rectum. The tissue

Table 4 Extent of descending perineum versus patient age

\begin{tabular}{lrl}
\hline Descending perineum (DP) & Number & $\begin{array}{l}\text { Median/average } \\
\text { age (years) }\end{array}$ \\
\hline No significant DP & 5 & $51 / 50$ \\
Descend above level of ischial tuberosities & 14 & $50 / 49$ \\
Reaches level of ischial tuberosities & 25 & $60 / 61$ \\
Descend beyond level of ischial tuberosities & 5 & $66 / 69$ \\
Not stated & 2 & \\
$\quad$ DP versus age & & $p=0.015$ \\
\hline
\end{tabular}


Table 5 Extent of hemorrhoid disease versus patient age

\begin{tabular}{lcccl}
\hline $\begin{array}{l}\text { Associated } \\
\text { hemorrhoidal } \\
\text { disease (HD) }\end{array}$ & Number & Male & Female & $\begin{array}{l}\text { Median/average } \\
\text { age (years) }\end{array}$ \\
\hline No significant HD & 8 & 0 & 8 & $55 / 56$ \\
Grade I & 9 & 2 & 7 & $60 / 60$ \\
Grade II & 21 & 7 & 14 & $53 / 56$ \\
Grade III & 8 & 2 & 6 & $59 / 60$ \\
Grade IV & 3 & 1 & 2 & $60 / 61$ \\
Not stated & 2 & 0 & 2 & \\
& HD versus age & & n.s. \\
\hline
\end{tabular}

trauma is most likely caused by shearing forces and ischemia caused by the intussusception.

The healthy rectum assumes an important sensory role in the physiology of defecation. There is consensus that increased intraluminal pressure in the rectum is perceived by receptors, although these have not been conclusively identified [15-19]. Above a certain threshold, rectal intraluminal pressure initiates the urge to defecate. The threshold for urge appears to be variable and may be influenced by acquired changes of the rectal wall (caused for example by inflammatory diseases, radiation, or acquired degenerative changes) [20-23].

Contrary to widely held beliefs, a physiologically intact rectum has no role as reservoir. However, with advancing age, acquired degenerative changes, and ensuing loss of evacuation strength, the rectum commonly mimics a stool-filled reservoir. The rectum acts as barrier to colonic peristalsis, which usually ends at the recto-sigmoid junction and is not propagated into the rectum [18]. During the resting phase, there appear to be retrograde propulsion motor complexes that transport smaller amounts of fecal matter back into the sigmoid colon until mass peristalsis from above is initiated [24]. Retrograde propulsive activity is also stimulated by the conscious suppression of defecation urge. A chronically stool- impacted rectum, which is a common finding, particularly in the elderly, can therefore be taken as evidence for a rectal evacuation deficit.

Evacuation of stool is also supported by active rectal motor activity. Defecation can be consciously initiated by the parasympathetic nervous system. To evacuate stool, the levator and anal sphincters relax, opening the anal canal. The rectum contracts mainly axially. To achieve axial contraction, colonic tenia spread anatomically over the rectum to form the external layer of the muscularis propria, which covers the entire organ. There is, however, also transverse peristalsis in the rectum brought about by contraction of the inner and more circular layer of the rectal muscularis propria [15-18].

The healthy rectum therefore has important and complex sensory and evacuation functions for defecation; proper sensory and motor functions require intact nerve and muscular structures in the wall of the rectum. Our findings confirm that rectal prolapse causes sufficient trauma to compromise these functions. This is perhaps not surprising if one considers the marked morphologic changes in an intussuscepting rectum. Dynamic defecography often reveals an extremely flaccid and dilated rectum in patients with rectal prolapse (Fig. 2).

Our finding that there is a positive correlation between age and the extent of internal rectal prolapse and rectocele strongly supports our opinion that the disorder is acquired and foremost a degenerative one. It may possibly be regarded as yet one more specific aspect of aging and be likened to other ageassociated degenerative disorders.

It is likely that prolapse formation starts as mucosal prolapse and that in many cases, a reduction of connective tissue tautness may contribute to it. The shearing forces exerted by the passage of flatus or fecal matter push and pull the obstructing mucosal folds, thereby gradually involving and progressively traumatizing the deeper layers of the rectal wall and initiating a vicious circle of obstruction and prolapse formation.

Mucosal prolapse is in turn linked to many proctologic disorders, in particular hemorrhoidal disease. This is the rationale

Table 6 Extent of anterior rectocele in female patients versus patient age

\begin{tabular}{|c|c|c|}
\hline Anterior rectocele (AR; females) & Number & $\begin{array}{l}\text { Median/ } \\
\text { average } \\
\text { age (years) }\end{array}$ \\
\hline No significant AR & 3 & $49 / 52$ \\
\hline Small (digital examination produces only slight bulging of rectovaginal wall (RVW) seen through the introitus) & 1 & 56 \\
\hline Medium (digital examination produces prominent bulging of RVW seen through the introitus) & 30 & $56 / 59$ \\
\hline $\begin{array}{l}\text { Advanced (digital examination produces bulging of RVW protruding externally through the introitus; RVW appears thin and } \\
\text { fibrosed) }\end{array}$ & 3 & $63 / 62$ \\
\hline \multirow[b]{2}{*}{ AR versus age } & 2 & \\
\hline & & n.s. \\
\hline
\end{tabular}


Table 7 Summary of neuropathologic and histopathologic findings in specimens taken during stapled transanal resection of the rectum

\begin{tabular}{lccc}
\hline Neuropathologic and histopathological defects & \multicolumn{2}{c}{ Number of specimens affected } \\
\cline { 2 - 4 } & Total & Ventral & Dorsal \\
\hline Number of specimens & 100 & 49 & 51 \\
Crypt atrophy & 14 & 8 & 6 \\
Fibromuscular obliteration of lamina propria & 14 & 10 & 4 \\
Atrophy of circular layer & 68 & 34 & 34 \\
Fibrosis of circular layer & 81 & 39 & 42 \\
Atrophy of longitudinal muscle layer & 35 & 14 & 21 \\
Fibrosis of longitudinal muscle layer & 65 & 29 & 36 \\
Rarification of Cajal cells & 27 & 14 & 13 \\
Fibrosis of myenteric plexus & 85 & 41 & 44 \\
Neuropathological defects classified as "moderate" or "advanced" & 49 & 25 & 24 \\
No neuronal defects & 10 & 6 & 4 \\
No muscular defects & 6 & 3 & 3 \\
Neither neuronal nor muscular defects & 4 & 3 & 1 \\
\hline
\end{tabular}

for undertaking stapled hemorrhoidopexy, as well as for ligation and injection sclerotherapy. Internal mucosal and ensuing rectal prolapse are therefore very common.

The formation of internal rectal prolapse invariably promotes physical and functional defecation obstruction. Obstruction may cause few symptoms, or even be asymptomatic, for many years. Obstruction usually evolves gradually, and the severity of its effects may ebb and flow, being influenced by factors such as diet, food allergies, laxative intake, and exercise. This explains why the obstructive effects of prolapse formation remain undetected in many patients and why the functional significance of these common degenerative changes is still a matter of much controversy.
That even near-to-complete obstruction of passage of fecal matter may cause few or no symptoms for a long time is not exclusive to patients with internal rectal prolapse. Patients with long-standing stenosing diverticular disease, Crohn's disease, or malignancies often report "normal" bowel function.

The degenerative process is usually not limited to the infolding rectal wall; it appears to gradually involve the entire rectum and may affect the pelvic floor and adjoining organs, particularly in women. This typically presents with associated phenomena such as a descending perineum. As the diameter of the pelvic outlet is smaller in men, a smaller amount of mucosal prolapse - as seen in hemorrhoidal disease - may result in significant obstruction.
Fig. 2 Defecographic sequence showing distortion of the rectal wall associated with internal rectal prolapse formation

\begin{tabular}{|l|l|}
\hline \multicolumn{2}{|c|}{ Terms used to describe rectal dysfunction in the context of constipation, incontinence and } \\
irritable bowel syndrome \\
\hline "rectal hyposensitivity" $13,14,17,18$ \\
\hline "rectal akinesia"15 & \\
\hline "rectal inertia" "19,20 & \\
\hline "idiopathic megarectum""16,35 & \\
\hline "dyssynergic defecation" & \\
\hline "altered rectal perception"34
\end{tabular}


There may be factors contributing to the development of internal rectal prolapse or rectocele, such as defecation disorders or a history of vaginal delivery and/or hysterectomy in women; however, numerous patients are affected without any obvious risk factors.

The acquired structural damage leads to impairment of rectal function, which may persist despite operative repair of the obstructing prolapse. The persistence of rectal dysfunction after surgery contributes to the ongoing debate about the optimal intervention for rectal prolapse. For many decades, this has been a matter of lively debate. It appears likely that the mode of operative repair, in particular whether the rectum is mobilized anteriorly, posteriorly, or circumferentially, may have little or no effect on functional outcome. Within the context of circular mobilization, the significance of the so-called lateral ligaments of the rectum has in particular been a matter of some controversy [25]. Whatever nerves these ligaments may contain, however, they may be of negligible significance in a prolapsing and therefore dysfunctional rectum.

The self-reinforcing sequence of physical and functional obstruction of the rectum may also explain why there have been consistent reports of marked motor and sensory disturbances of the rectum detected in patients with constipation, defecation obstruction, fecal incontinence, and irritable bowel syndrome (Fig. 2) [26-36].

Internal rectal prolapse is common, and therefore, rectal dysfunction is common. It is an often unrecognized and possibly to a certain extent unavoidable consequence of aging that affects men and women alike. It initiates a vicious circle of physical obstruction and functional impairment. Progressive impairment of rectal evacuation and the ensuing fecal congestion cause the typical symptom overlap of constipation and incontinence. The current strategy of evaluating and treating constipation and fecal incontinence as two distinct disorders needs to be reviewed in the light of this.

An understanding that rectal evacuation depends on an intact rectum, and that over time, the rectum is as prone as any other organ to age-related progressive degeneration in structure and function, increases our understanding of constipation and incontinence - particularly in the elderly. Both disorders significantly impair quality of life and are also of considerable socioeconomic relevance.

Acknowledgments The authors thank the Institute of Biostatistics and Clinical Research, Westfälische Wilhelms-Universität, Münster, Germany, for the statistical support.

\section{Compliance with ethical standards}

Conflict of interest The authors declare that they have no conflict of interest.
Open Access This article is distributed under the terms of the Creative Commons Attribution 4.0 International License (http:// creativecommons.org/licenses/by/4.0/), which permits unrestricted use, distribution, and reproduction in any medium, provided you give appropriate credit to the original author(s) and the source, provide a link to the Creative Commons license, and indicate if changes were made.

\section{References}

1. Arroyo A, Pérez-Vicente F, Serrano P, Sánchez A, Miranda E, Navarro JM, Candela F, Calpena R (2007) Evaluation of the stapled transanal rectal resection technique with two staplers in the treatment of obstructive defecation syndrome. J Am Coll Surg 204:56-63

2. Arroyo A, González-Argenté FX, García-Domingo M, EspinBasany E, De-la-Portilla F, Pérez-Vicente F, Calpena R (2008) Prospective multicentre clinical trial of stapled transanal rectal resection for obstructive defaecation syndrome. Br J Surg 95:15211527. doi:10.1002/bjs. 6328

3. Boccasanta P, Venturi M, Salamina G, Cesana BM, Bernasconi F, Roviaro G (2004) Int J Color Dis 19:359-369

4. Corman ML, Carriero A, Hager T, Herold A, Jayne DG, Lehur PA, Lomanto D, Longo A, Mellgren AF, Nicholls J, Nyström PO, Senagore AJ, Stuto A, Wexner SD (2006) Consensus conference on the stapled transanal rectal resection (STARR) for disordered defaecation. Color Dis 8:98-101

5. Ellis CN (2007) Stapled transanal rectal resection (STARR) for rectocele. J Gastrointest Surg 11:153-154

6. Frascio M, Stabilini C, Ricci B, Marino P, Fornaro R, De Salvo L, Mandolfino F, Lazzara F, Gianetta E (2008) Stapled transanal rectal resection for outlet obstruction syndrome: results and follow-up. World J Surg 32:1110-1115. doi:10.1007/s00268-008-9540-x

7. Ganeshan A, Anderson EM, Upponi S, Planner AC, Slater A, Moore N, D'Costa H, Bungay H (2008) Imaging of obstructed defecation. Clin Radiol 63:18-26

8. Ommer A, Albrecht K, Wenger F, Walz MK (2006) Stapled transanal rectal resection (STARR): a new option in the treatment of obstructive defecation syndrome. Langenbeck's Arch Surg 391:32-37

9. Pechlivanides G, Tsiaoussis J, Athanasakis E, Zervakis N, Gouvas N, Zacharioudakis G, Xynos E (2007) Stapled transanal rectal resection (STARR) to reverse the anatomic disorders of pelvic floor dyssynergia. World J Surg 31:1329-1335

10. Schwandner O, Fürst A (2008) Aktueller Stellenwert der transanalen Stapler-Resektion des distalen Rektums (STARR) bei Obstruktivem Defäkations-Syndrom. Zentralbl Chir 13:116-122. doi:10.1055/s-2008-1004736

11. Schwandner O, Stuto A, Jayne D, Lenisa L, Pigot F, Tuech JJ, Scherer R, Nugent K, Corbisier F, Basany EE, Hetzer FH (2008) Decision-making algorithm for the STARR procedure in obstructed defecation syndrome: position statement of the group of STARR pioneers. Surg Innov 15:105-109. doi:10.1177/1553350608316684

12. Slim K, Mezoughi S, Launay-Savary MV, Tuech JJ, Michot F, Sielezneff I, Sastre B, Pigot F, Juguet F, Faucheron JL, Voirin D, Chipponi J (2008) Traitement de la rectocèle par résection rectale transanale à la pince mécanique: résultats à moyen terme d'une étude multicentrique en France. J Chir 145:27-31

13. Knowles CH, De Giorgio R, Kapur RP, Bruder E, Farrugia G, Geboes K, Gershon MD, Hutson J, Lindberg G, Martin JE, Meier-Ruge WA, Milla PJ, Smith VV, Vandervinden JM, Veress B, Wedel T (2009) Gastrointestinal neuromuscular pathology: guidelines for histological techniques and reporting on behalf of the Gastro 2009 International Working Group. Acta Neuropathol 118:271-301. doi:10.1007/s00401-009-0527-y 
14. Stolte M, Rüschoff J, Klöppel G 2013 (Publ). Gastrointestinal neuromuscular pathology in chronic constipation; diverticular disease is associated with an enteric neuropathy as revealed by morphometric analysis; desmosis of the colon: a working hypothesis of primary chronic constipation Verdauungstrakt und Peritoneum (Book). Springer Verlag ISBN 978-3-642-02321-7. doi: 10.1007/978-3642-02322-4

15. Henry MM (1985) ISBN 978-0407003521 (Hg). Coloproctology and the pelvic floor. Butterworth-Heinemann, Oxford, pp. 93-94

16. Mazier WP (1995) ISBN 978-0-7216-4689-3 (Hg). Surgery of the colon, rectum, and anus. Saunders, Philadelphia, p. p1075

17. Nicholls RJ, Dozois RR (1997) ISBN 0-443-05565-3 (Hg). Surgery of the colon \& rectum. Churchill Livingstone, New York, pp. 15-16

18. Pulit S, Lunniss PJ, Scott SM (2012) The physiology of human defecation. Dig Dis Sci 57:1445-1464. doi:10.1007/s10620-0122071-1

19. Sabate JM, Coffin B, Jian R, Le Bars D, Bouhassira D (2000) Rectal sensitivity assessed by a reflexologic technique: further evidence for two types of mechanoreceptors. Am J Physiol Gastrointest Liver Physiol 279:G692-G699

20. van Nieuwenhoven MA, Kilkens TO (2012) The effect of acute serotonergic modulation on rectal motor function in diarrheapredominant irritable bowel syndrome and healthy controls. Eur J Gastroenterol Hepatol 24:1259-1265. doi:10.1016/j. bpg.2011.01.001

21. Krol R, Hopman WP, Smeenk RJ, Van Lin EN (2012) Increased rectal wall stiffness after prostate radiotherapy: relation with fecal urgency. Neurogastroenterol Motil 24:339-e166. doi:10.1111 /j.1365-2982.2011.01858.x

22. Sloots CE, Felt-Bersma RJ, West RL, Kuipers EJ (2005) Stimulation of defecation: effects of coffee use and nicotine on rectal tone and visceral sensitivity. Scand J Gastroenterol 40:808-813

23. Yeoh EK, Bartholomeusz DL, Holloway RH, Fraser RJ, Botten R, Di Matteo A, Moore JW, Schoeman MN (2010) Disturbed colonic motility contributes to anorectal symptoms and dysfunction after radiotherapy for carcinoma of the prostate. Int J Radiat Oncol Biol Phys 78:773-780. doi:10.1016/j.ijrobp.2009.08.050

24. Rao S, Welcher K (1996) Periodic rectal motor activity: the intrinsic colonic gatekeeper? Am J Gastroenterol 91:890-897

25. Charran O, Muhlemann M, Shah S, Tubbs RS, Loukas M (2014) Ligaments of the rectum: anatomical and surgical considerations. Am Surg 80:275-283
26. Burgell RE, Lelic D, Carrington EV, Lunniss PJ, Olesen SS, Surguy S, Drewes AM, Scott SM (2013) Assessment of rectal afferent neuronal function and brain activity in patients with constipation and rectal hyposensitivity. Neurogastroenterol Motil 25:260-267. doi:10.1111/nmo.12047

27. Burgell RE, Bhan C, Lunniss PJ, Scott SM (2012) Fecal incontinence in men: coexistent constipation and impact of rectal hyposensitivity. Dis Colon rectum 55:18-25. doi:10.1097/DCR.0 b013e318237f37d

28. Faucheron JL, Dubreuil A (2000) Rectal akinesia as a new cause of impaired defecation. Dis Colon rectum 43:1545-1549

29. Gladman MA, Williams NS, Scott SM, Ogunbiyi OA, Lunniss PJ (2005) Medium-term results of vertical reduction rectoplasty and sigmoid colectomy for idiopathic megarectum. Br J Surg 92:624630

30. Knowles CH, Thin N, Gill K, Bhan C, Grimmer K, Lunniss PJ, Williams NS, Scott SM (2012) Prospective randomized doubleblind study of temporary sacral nerve stimulation in patients with rectal evacuatory dysfunction and rectal hyposensitivity. Ann Surg 255:643-649. doi:10.1097/SLA.0b013e318247d49f

31. Lee TH, Lee JS, Hong SJ, Jeon SR, Kwon SH, Kim WJ, Kim HG, Cho WY, Cho JY, Kim JO, Lee JS (2013) Rectal hyposensitivity and functional anorectal outlet obstruction are common entities in patients with functional constipation but are not significantly associated. Korean J Intern Med 28:54-61. doi:10.3904 /kjim.2013.28.1.54

32. Scott SM, van den Berg MM, Benninga MA (2011) Rectal sensorimotor dysfunction in constipation. Best Pract Res Clin Gastroenterol 25:103-118. doi:10.1016/j.bpg.2011.01.001

33. Shafik A, Ahmed I (2002) Study of the motile activity of the colon in rectal inertia constipation. J Gastroenterol Hepatol 17:270-275

34. Posserud I, Syrous A, Lindström L, Tack J, Abrahamsson H, Simrén M (2007) Altered perception in irritable bowel syndrome is associated with symptom severity. Gastroenterology 133:1113-1123

35. Williams NS, Fajobi OA, Lunniss PJ, Scott SM, Eccersley AJ, Ogunbiyi OA (2000) Vertical reduction rectoplasty: a new treatment for idiopathic megarectum. Br J Surg 87:1203-1208

36. Woodward S, Norton C, Chiarelli P (2014) Biofeedback for treatment of chronic idiopathic constipation in adults. Cochrane Database Syst Rev 26(3):CD008486. doi:10.1002/14651858. CD008486.pub2 